\title{
USO DE TÉCNICAS DE GEOPROCESSAMENTO PARA O DIAGNÓSTICO DA OCUPAÇÃO DO SOLO EM ÁREAS DE PRESERVAÇÃO PERMANENTE DE UMA MICROBACIA HIDROGRÁFICA
}

\author{
Felipe de Souza Nogueira Tagliarini ${ }^{1}$
}

\author{
Mikael Timóteo Rodrigues ${ }^{2}$
}

Yara Manfrin Garcia ${ }^{3}$

\begin{abstract}
RESUMO
O presente estudo teve como objetivo identificar os usos e ocupação do solo e os consequentes conflitos de uso nas áreas de preservação permanente (APP) da microbacia hidrográfica do Córrego do Petiço, inserida no município de Botucatu-SP. Para tal, foi utilizada a imagem do satélite LANDSAT-8, sensores OLIS e TIR, bandas 4, 5 e 6 de 23 de agosto de 2013, cedida pelo U.S. Department of the Interior/U.S. Geological Survey. O sistema de informação geográfica (SIG) utilizado foi o IDRISI Selva, para o manuseio dos arquivos matriciais e o software CartaLinx para os dados vetoriais. O aporte legal foi embasado na legislação florestal atual, Lei Federal $n^{\circ} 12.651 / 12$, com alterações feitas pela Lei Federal $n^{\circ} 12.727 / 12$. Foi observado que as APP não estão integralmente preservadas como preza o código florestal, onde 19,86 \% (56,54 ha) das zonas de APP estão ocupadas com usos conflitantes. Dentro deste contexto, são necessárias medidas mitigatórias para a proteção dos recursos hídricos no Córrego do Petiço, como técnicas de recuperação de áreas degradas e restauração florestal nas nascentes e trechos ao longo dos cursos d'água degradados, pois a degradação de tais áreas pode por em risco o funcionamento hídrico da microbacia a médio-longo prazo.
\end{abstract}

PALAVRAS-CHAVE: Geotecnologias. Código Florestal. Preservação Ambiental.

\footnotetext{
${ }^{1}$ Graduando em Engenharia Florestal - Faculdade de Ciências Agronômicas (UNESP/FCA). E-mail: felipe_tagliarini@hotmail.com

${ }^{2}$ Doutorando do Programa de Pós Graduação em Agronomia - Energia na Agricultura - Faculdade de Ciências Agronômicas (UNESP/FCA). E-mail: mikaelgeo@gmail.com

${ }^{3}$ Doutoranda do Programa de Pós Graduação em Agronomia - Energia na Agricultura - Faculdade de Ciências Agronômicas (UNESP/FCA). E-mail: yaramanfrin@hotmail.com
} 


\title{
USE OF GEOPROCESSING TECHNIQUES FOR DIAGNOSIS OF SOIL OCCUPATION IN PERMANENT PRESERVATION AREAS OF A WATERSHED
}

\begin{abstract}
The present study aimed to identify the uses and occupation of soil and the resulting conflicts of use in permanent preservation areas (PPA) of the watershed Córrego do Petiço, inserted in Botucatu-SP. For this, was used satellite image of the LANDSAT-8, sensors OLIS and TIR, bands 4, 5 and 6 of August 23, 2013, ceded by the U.S. Department of the Interior/U.S. Geological Survey. The geographic information system (GIS) used was the IDRISI Selva, for handling raster files and the software CartaLinx for vector data. The legal support was based on the current forest legislation, Federal Law no 12,651/12, with changes made by the Federal Law $n=12,727 / 12$. It was observed that the PPA are not fully preserved as governed in the forest code, where $19.86 \%$ (56.54 ha) of zones of PPA is occupied with conflicting uses. Within this context, mitigation measures is necessary for the protection of water resources in the Córrego do Petiço, as techniques for recovery of degraded areas and forest restoration, because the degradation of such areas may put at risk the hydric functioning of the watershed in medium-long period.
\end{abstract}

\section{USO DE TÉCNICAS DE GEOPROCESAMIENTO PARA EL DIAGNÓSTICO DE LA OCUPACIÓN DE SUELOS EN ÁREAS DE PRESERVACIÓN PERMANENTE PARA UNA MICROCUENCA}

\begin{abstract}
RESUMEN
El presente estudio tuvo como objetivo identificar los usos y ocupación del suelo y los conflictos derivados de su uso en áreas de preservación permanente (APP) de la microcuenca Córrego do Petiço, insertada en municipio de Botucatu-SP. Para esto, fue utilizada la imagen del satélite LANDSAT-8, sensores OLIS y TIR, bandas 4, 5 e 6 de 23 de agosto de 2013, cortesía del U.S. Department of the Interior/U.S. Geological Survey. El sistema de información geográfica (SIG) usado fue el IDRISI Selva, para la manipulación de archivos raster y el software CartaLinx para datos vectoriales. El aporte legal fue basado en la legislación forestal vigente, Ley Federal № 12.651/12, con cambios realizados por la Ley Federal № 12.727/12. Se observó que las APP no están totalmente preservada como regula el código forestal, donde 19,86 \% (56,54 ha) de las zonas de APP están ocupados con usos conflictivos. En este contexto, medidas de mitigación son necesarias para la protección de los recursos hídricos en el Córrego do Petiço, como técnicas de recuperación de áreas degradadas y restauración forestal en las nacientes y tramos a lo largo de los cursos de agua degradados, porque la degradación de estas áreas puede poner en peligro el funcionamiento hídrico de la microcuenca en medio-largo plazo.
\end{abstract}

PALABRAS-CLAVE: Geotecnologías. Código Forestal. Preservación Ambiental.

\section{INTRODUÇÃO}


A preocupação mundial a cerca da alta taxa de desmatamento nas florestas tropicas e o seu impacto na biodiversidade tem aumentado consideravelmente nas últimas décadas. Por este motivo, foram criadas em lei as áreas de preservação permanente (APP) com o intuito de evitar a degradação do ecossistema, promover a conservação do ambiente natural e a manutenção da qualidade de vida (CAMPOS et al., 2013).

Segundo Garcia (2011) legislação florestal brasileira está entre as mais completas e avançadas do mundo, seu desenvolvimento está de acordo com a importância que a preservação do meio ambiente vem ganhando profundidade frente às questões ambientais, sendo assim, uma das mais discutidas na atualidade por exercer impacto direto na qualidade de vida dos seres vivos.

Portanto, torna-se vital o conhecimento, análise e prática da Lei $\mathrm{n}^{\circ} 12.727$, que pode ser tratada como o primeiro passo quando se fala em gestão ambiental e sustentabilidade. Esta Lei, em seu art. $1^{0}$ "estabelece normas gerais sobre a proteção da vegetação, Áreas de Preservação Permanente (APP) e as áreas de Reserva Legal; a exploração florestal, o suprimento de matéria-prima florestal, o controle da origem dos produtos florestais e o controle e prevenção dos incêndios florestais, e prevê instrumentos econômicos e financeiros para o alcance de seus objetivos" (BRASIL, 2012).

Tais áreas, em diversos casos, como em relação à declividade, topos de morros, margens dos recursos hídricos e nascentes dos mananciais, não têm sido devidamente respeitadas, devido ao uso inadequado dos recursos naturais. Os recursos naturais, solos férteis $e$ as florestas nativas remanescentes foram intensamente reduzidos na maioria das APP, em muitos casos, pelo desconhecimento da população e por sua incorreta interpretação do Código Florestal (CAMPOS et al., 2013).

De acordo com Silva (1996) as áreas de preservação permanente foram criadas para proteger o meio ambiente na sua forma natural, através da delimitação das áreas impróprias para o uso da terra, a fim de manter a cobertura vegetal original, a qual será responsável por atenuar os efeitos erosivos, a lixiviação dos nutrientes no 
solo e o assoreamento, além de contribuir para regularizar a vazão dos cursos d'água, trazendo benefícios para a fauna silvestre.

A utilização do geoprocessamento como ferramenta é bastante eficaz na espacialização e quantificação dos recursos naturais de uma determinada área tanto a nível regional quanto a nível local, abrangendo o planejamento e emprego adequado da ocupação de determinado perímetro, assim se tornando uma alternativa viável na restrição das possíveis falhas e lacunas referentes à implementação das leis em anexo as áreas de preservação permanente.

Os sistemas de informações geográficas (SIG) têm colaborado para o mapeamento e zoneamento, atuando como método de fiscalização da vegetação nativa em vastas áreas de APP e seus respectivos espaços conflitantes e o uso da terra, uma vez que as mudanças ocorrem em uma pequena escala temporal. Segundo Pinto et al. (2005), a análise minuciosa do uso inadequado do solo é de grande importância, tendo em vista que boa parte das propriedades rurais apresenta algum tipo de uso conflitante.

Neste contexto, o presente trabalho teve como objetivo avaliar os múltiplos tipos de uso e ocupação do solo na microbacia hidrográfica do Córrego do Petiço, Botucatu-SP, com ênfase nas áreas hídricas de preservação permanente (cursos d'água e nascentes) com a finalidade de identificar a ocorrência de áreas com uso e ocupação do solo que evidenciam conflito, por intermédio de SIG e da legislação florestal brasileira.

\section{MATERIAIS E MÉTODOS}

A microbacia do Córrego Petiço (Figura 1) localiza-se no município de Botucatu-SP, possui uma área total de 3385,20 ha, com situação definida nas coordenadas geográficas $48^{\circ} 20^{\prime} 23^{\prime \prime}$ a $48^{\circ} 15^{\prime} 12^{\prime \prime}$ de longitude W Gr. e $22^{\circ} 51^{\prime}$ ' $51^{\prime \prime}$ a $22^{\circ} 46^{\prime} 54^{\prime \prime}$ de latitude $S$.

Figura 1: Localização do Córrego do Petiço. 


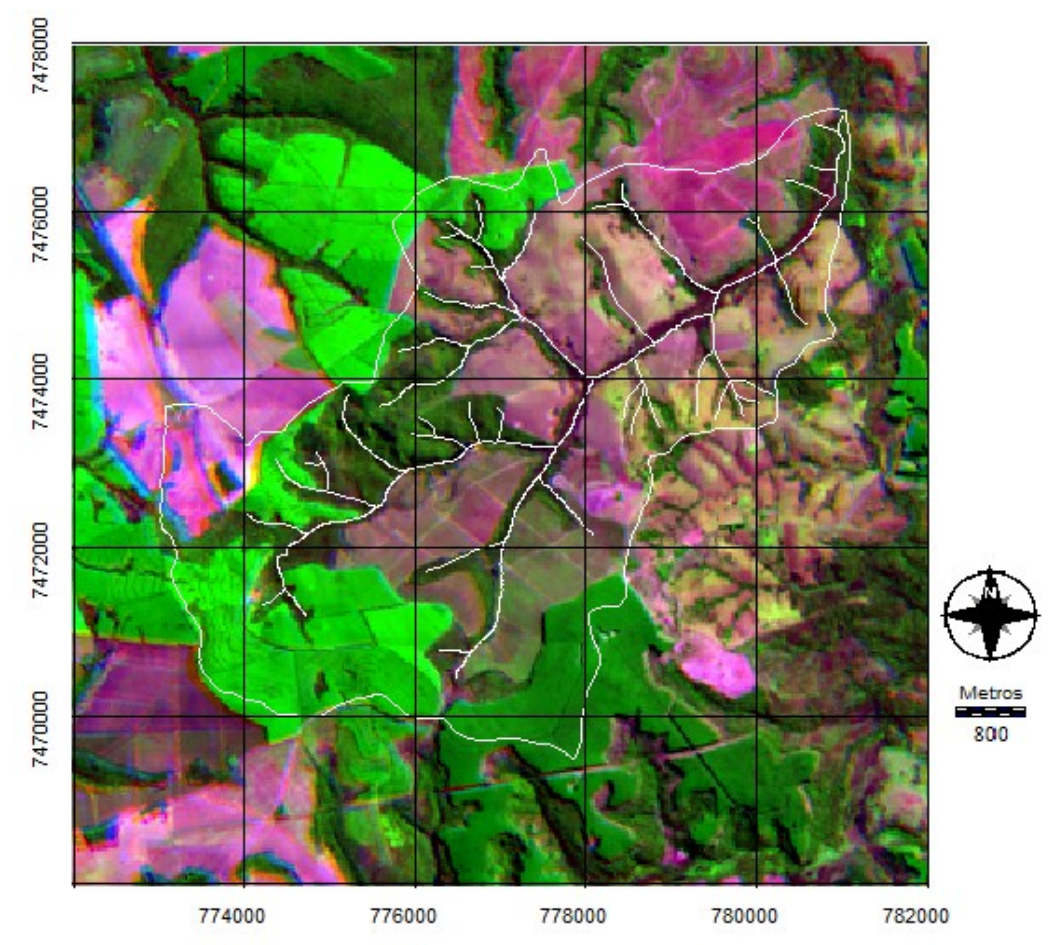

A classificação climática de Köppen, para a área é temperado quente (mesotérmico) úmido, do tipo Cwa, com chuvas no verão e seca no inverno, possui precipitação média anual de $1358,6 \mathrm{~mm}$ e temperatura média anual de $20,7{ }^{\circ} \mathrm{C}$ (CEPAGRI, 2014).

Os tipos de solos ocorrentes na área, de acordo com Piroli (2002) foram classificados como: Neossolo Quartizarêncico órtico (RQotípico), Gleissolo Háplico Tb distrófico (GXbd), Neossolo Litólico eutrófico (RLe) e Argissolo Vermelho-Amarelo distrófico abrupto $\left(\mathrm{PVAd}_{2}\right)$.

A delimitação do limite da área da microbacia foi realizada através da carta planialtimétrica em formato digital, confeccionada pelo Instituto Brasileiro de Geografia e Estatística - IBGE (1969) referente à folha de Botucatu (SF-22-Z-B-VI-3), na escala 1:50.000 com equidistância entre as curvas de nível de $20 \mathrm{~m}$ onde obteve-se os pontos de controle (coordenadas) para o georreferenciamento através do módulo Reformat/Resample do IDRISI. A digitalização do limite da microbacia hidrográfica foi realizado empregando-se o software CartaLinx.

Foi elaborada uma composição falsa cor com a combinação das bandas 4,5 e 6, obtidas a partir da imagem do satélite LANDSAT-8, sensores OLIS e TIR, da 
órbita 220, ponto 76, com passagem em 23 de agosto de 2013, obtidas no catálogo de imagens do U.S. Department of the Interior/U.S. Geological Survey. Esta composição apresenta os corpos d'água em tons azulados, as florestas e outras formas de vegetações em tons esverdeados e os solos expostos em tons avermelhados, pois estas apresentam um melhor conforto visual e melhor discriminação dos alvos. O processo de georreferência consistiu em identificação das coordenadas na projeção UTM na carta topográficas de Botucatu bem como georreferenciamento das bandas 4, 5 e 6 da imagem orbital. Com estas informações gerou-se um arquivo de correspondência pelo módulo Data Entry/Edit, com as coordenadas $\mathrm{X}$ e $\mathrm{Y}$ de tela e seus correspondentes através do módulo Reformat/Resample.

Após o georreferenciamento das bandas, efetuou-se o recorte pela opção Reformat/Window extraindo assim apenas a área da bacia. Com as bandas das imagens georreferenciadas, foi realizado o processo de composição da imagem RGB (Red, Green, Blue), respectivamente das bandas 6, 5 e 4, utilizando-se da função Composite do menu Display do IDRISI Selva.

A carta topográfica e a composição foram exportados para o software CartaLinx - comando File/lmage Conversions e posteriormente começou-se a delimitar os elementos (coverages) - nascentes e rede de drenagem pela carta topográfica e delimitação dos usos do solo na composição - sendo que para os usos foram criados polígonos, enquanto que para a rede de drenagem linhas e para as nascentes pontos.

No IDRISI, definiram-se as APP ao longo dos cursos d'água e ao redor das nascentes da microbacia. Os buffers foram criados no menu GIS Analysis, ferramenta Distance Operators - BUFFER. Para isso, foi necessário repetir esse passo duas vezes, sendo uma para os cursos d'água e outra para as nascentes. Assim, criandose um buffer de raio de $50 \mathrm{~m}$ circulando as áreas das nascentes e um buffer de $30 \mathrm{~m}$ de cada lado da margem na drenagem ao longo do leito do córrego (medidas estas estipuladas pela Lei Florestal $n^{\circ} 12.727$ ), resultando no mapa de APP.

Para identificar as áreas de conflitos de uso do solo em APP, utilizou-se a álgebra de mapas realizando uma sobreposição do mapa de uso e ocupação do solo 
com o mapa das APP. Os procedimentos foram executados no IDRISI utilizando-se a ferramenta Mathematical Operators - OVERLAY do menu GIS Analysis e selecionouse a opção matemática First $x$ Second. Após a sobreposição desses mapas, as áreas de ocorrência dos conflitos de acordo com as classes de uso foram devidamente quantificadas, executando as funções de cálculo de área, pela ferramenta Area do menu Database Query, pertencente ao módulo Analysis do IDRISI. Foram consideradas sob uso conflitante as áreas ocupadas com outros fins presentes nas APP das nascentes e cursos d'água.

\section{RESULTADOS E DISCUSSÃO}

O mapeamento do uso da terra a partir das imagens de satélite do LANDSAT8 permitiu identificar seis classes de uso e ocupação do solo, como podem ser observados na Tabela 1 , onde a principal ocorrência de uso do solo corresponde ao reflorestamento com 43,70 \% seguido pela mata ciliar e pastagem com $28,56 \%$ e $24,56 \%$ respectivamente.

Tabela 1: Usos e ocupação do solo na microbacia do Córrego do Petiço.

\begin{tabular}{c|c|c}
\hline Categoria & Área (ha) & Porcentagem (\%) \\
\hline Mata ciliar & 966,91 & $\mathbf{2 8 , 5 6}$ \\
\hline Reflorestamento & 1479,22 & 43,70 \\
\hline Pastagem & 831,42 & 24,56 \\
\hline Várzea & 81,13 & 2,40 \\
\hline Mata (fragmentos de vegetação nativa) & 23,07 & 0,68 \\
\hline Represa & 3,45 & 0,10 \\
\hline Total & $\mathbf{3 3 8 5 , 2 0}$ & $\mathbf{1 0 0}$ \\
\hline
\end{tabular}

As áreas de mata (fragmentos de vegetação nativa) apresentam apenas vestígios de sua cobertura vegetal original, totalizando apenas 0,68 \% (23,07 ha) da área total da bacia, onde vestígios de Mata Atlântica e as planícies de Cerrados diminuem progressivamente devido principalmente a expansão de atividades como o 
Volume 10, Número 2, 2014

Bacias Hidrográficas, Planejamento e Gestão dos Recursos Hídricos

reflorestamento (eucalipto), com uma área de 1479,22 ha e a criação extensiva de gado, com área de 831,42 ha, como pode ser observado na Figura 2.

Figura 2: Uso e ocupação do solo no Córrego do Petiço.

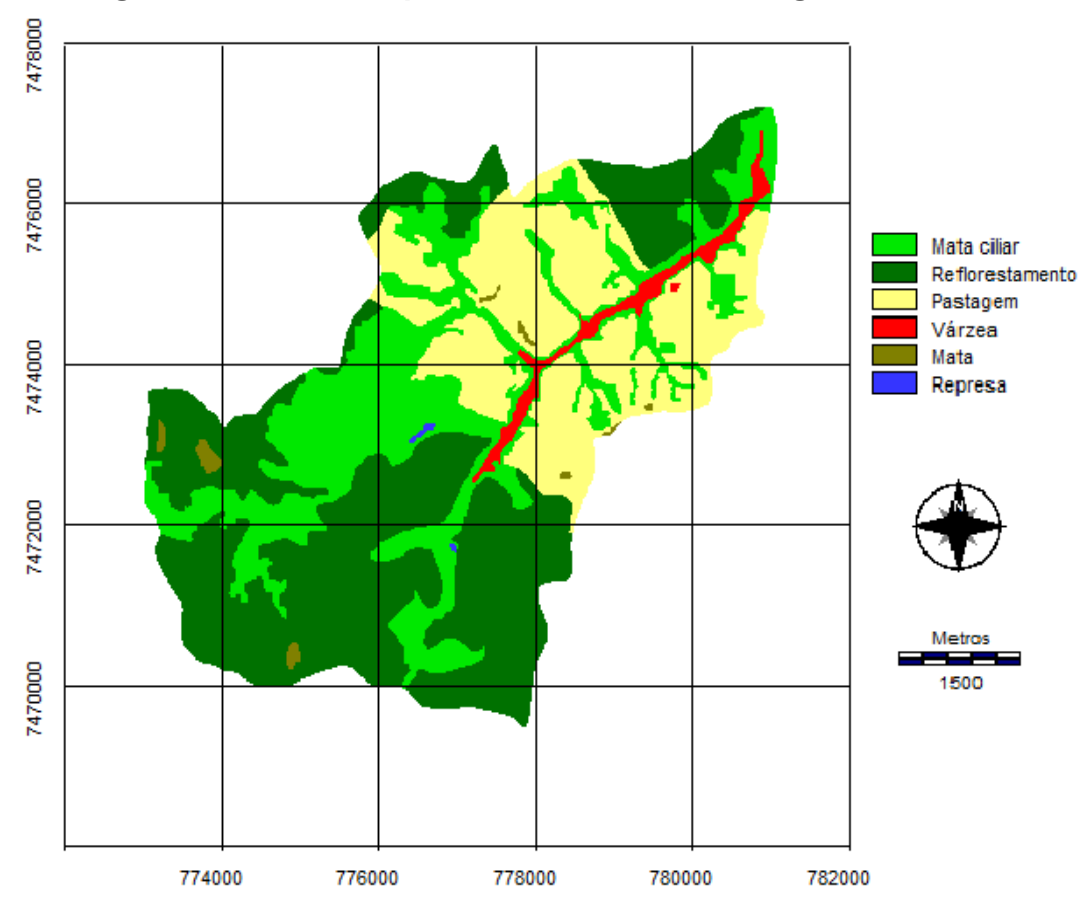

Apesar de porcentagens elevadas nos mais diversos usos da terra e praticamente a inexistência de práticas conservacionistas de solo nas áreas de pastagem, as áreas de mata ciliar e mata (fragmentos de vegetação nativa) se encontram na ordem de $29,34 \%$ (989,98 ha) da cobertura da do microbacia do Córrego Petiço, pois além da existência de APP e reservas legais, torna-se fundamental que esteja coberta por tais grupos de vegetação, onde estes reduzem o transporte de material nos cursos d'água, o assoreamento em suas margens, minimizando processos erosivos (SILVA, 1996).

O total de APP na microbacia do Córrego do Petiço, somando-se os $30 \mathrm{~m}$ de cada margem dos cursos d'água mais os $50 \mathrm{~m}$ de raio em cada nascente, conforme a Lei $n^{0} 12.727$ rege, tem-se um total de 284,77 ha (Figura 3 ). 
Figura 3: Extensão total das zonas de APP no Córrego do Petiço

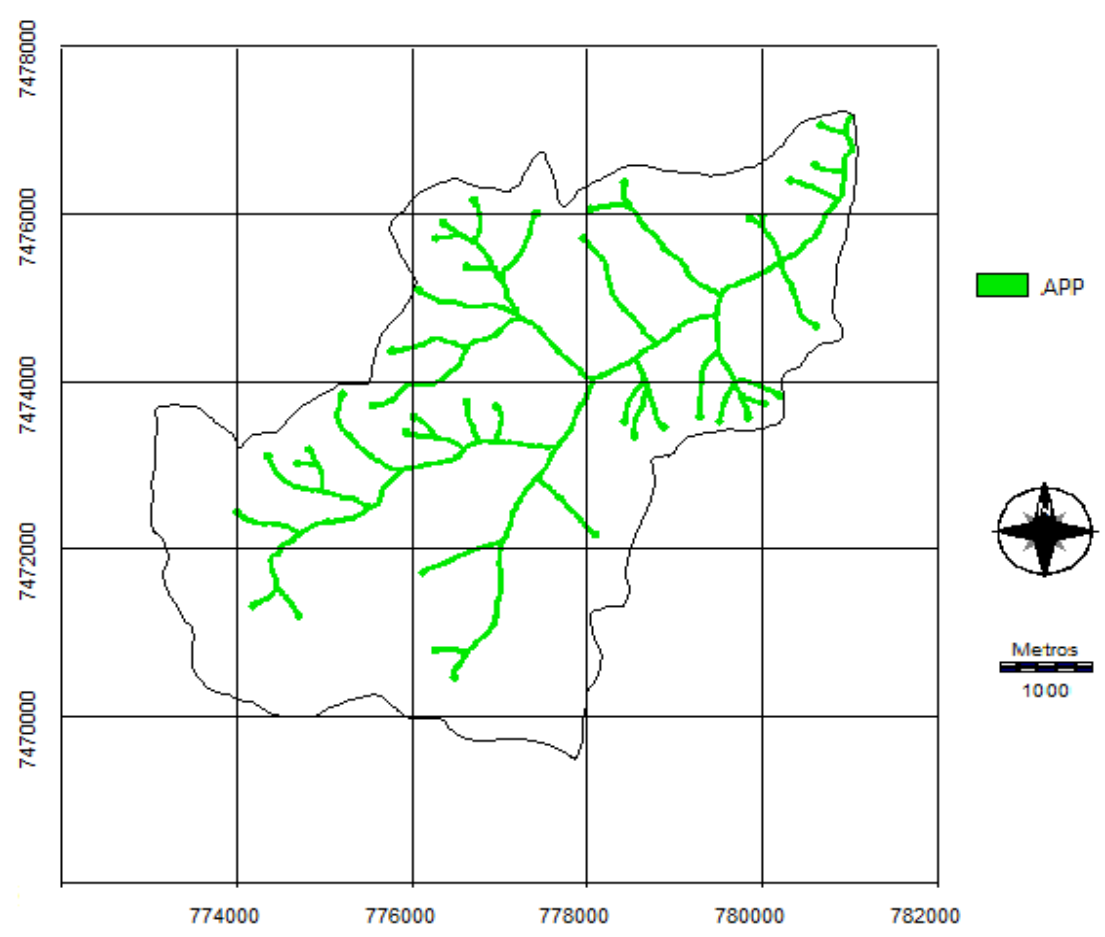

As APP dos leitos dos rios e suas respectivas nascentes estão ocupadas por poucos usos conflitantes da terra, porém que representam expressiva área, assim sendo considerado de grande impacto negativo, pois essas áreas se mal manejadas podem causar contaminação das águas, comprometendo sua qualidade, além de assoreamento dos cursos d'água afetando no futuro a demanda hídrica da microbacia.

Vale ressaltar que no desenvolvimento do presente estudo, os conflitos de uso da terra em áreas de preservação permanente foram analisados somente ao longo da rede de drenagem e nascentes da bacia (APP hídricas), não sendo analisadas as categorias de APP situadas no terço superior dos morros e encostas com declividade superior a $45^{\circ}$, conforme itens dos artigos $2^{\circ}$ e $3^{\circ}$ da Resolução $n^{\circ}$ 303 do CONAMA.

Do total de APP, estão sendo utilizadas de maneira incorreta, principalmente no que se refere à proteção dos cursos d'água com base na Lei Florestal, 19,86 \% (56,54 ha), como pode ser observado na Tabela 2. A vegetação nativa vêm sendo alvo das atividades antrópicas, gerando interesses conflitantes de uso e ocupação do 
Volume 10, Número 2, 2014

Bacias Hidrográficas, Planejamento e Gestão dos Recursos Hídricos

solo, ocasionando na supressão de parte da vegetação ao longo dos cursos d'água e nas nascentes, principalmente nas áreas que fazem divisa com pastagens (Figura 4).

Tabela 2: Usos e ocupação do solo na zona de APP da microbacia do Córrego do Petiço.

\begin{tabular}{c|c|c|c|c}
\hline \multirow{2}{*}{ Categoria } & \multicolumn{2}{|c|}{ APP } & \multicolumn{2}{c}{ Conflito } \\
\cline { 2 - 5 } & Área (ha) & Porcentagem (\%) & Área (ha) & Porcentagem (\%) \\
\hline Mata ciliar & 191,70 & 67,32 & - & - \\
\hline Reflorestamento & 13,80 & 4,85 & 13,80 & 24,41 \\
\hline Pastagem & 42,74 & 15,01 & 42,74 & 75,59 \\
\hline Várzea & 34,33 & 12,06 & - & - \\
\hline $\begin{array}{c}\text { Mata (fragmentos de } \\
\text { vegetação nativa) }\end{array}$ & 0,05 & 0,02 & - & - \\
\hline Represa & 2,15 & 0,75 & - & - \\
\hline Total & $\mathbf{2 8 4 , 7 7}$ & $\mathbf{1 0 0}$ & $\mathbf{5 6 , 5 4}$ & $\mathbf{1 0 0}$ \\
\hline
\end{tabular}

Figura 4: Conflito de uso e ocupação do solo nas zonas de APP no Córrego do Petiço.

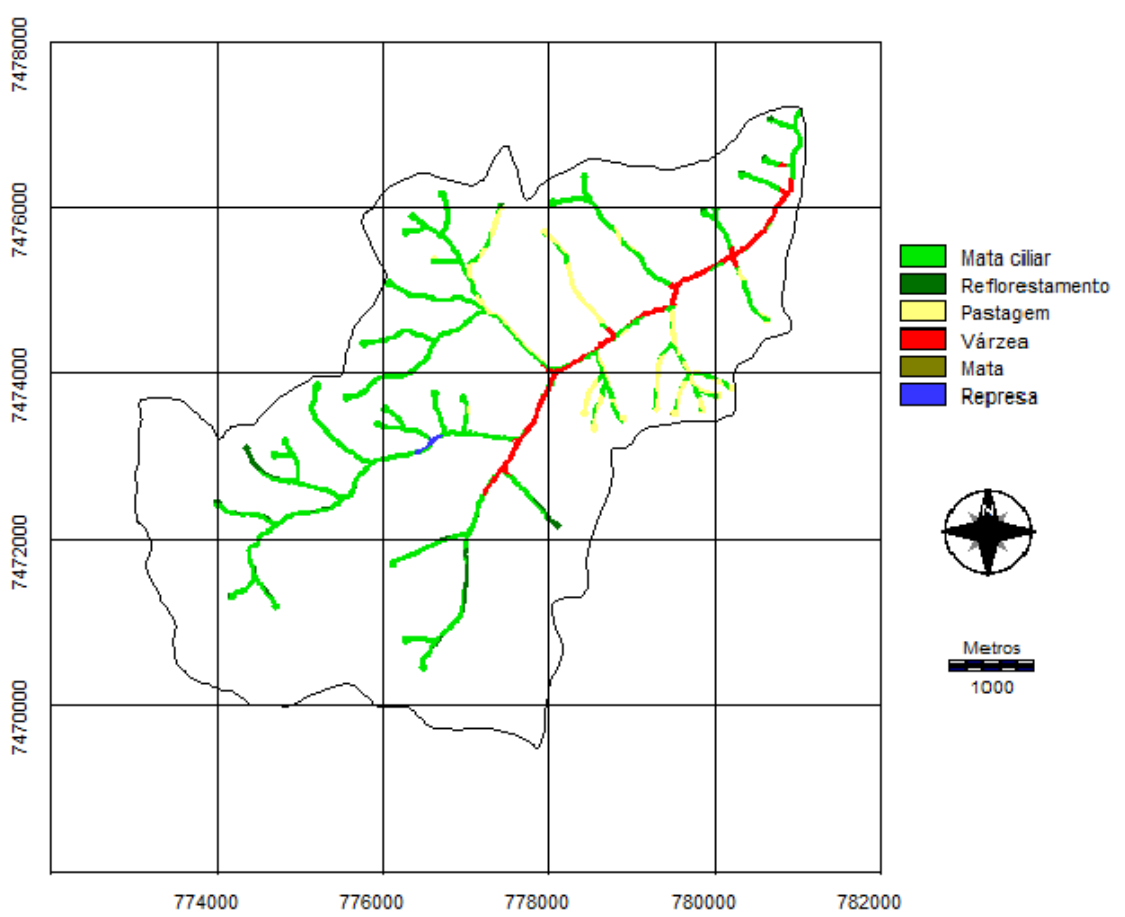

Como pode ser observado, dos $100 \%$ das áreas de preservação permanente do Córrego do Petiço, 67,32 \% são referentes à mata ciliar. A pastagem invadiu boa parte da área, contribuindo na ordem de $15,01 \%$, ocorrendo tanto em nascentes como 
ao longo de cursos d'água, onde a mesma se constitui como cobertura vegetal totalmente indevida por ser um agente degradante devido à menor proteção do solo, lenta regeneração natural e manejo indevido.

Além das pastagens, outra atividade de caráter conflitante encontrada ocupando as nascentes e margens dos cursos d'água, porém em menor escala de degradação é o reflorestamento com 4,85 \% (13,80 ha), tendo como pressuposição de que conforme a legislação vigente, os valores de conflito de uso do solo em APP deveriam ser iguais à zero. Porém vale resaltar que onde há divisa de APP com áreas de reflorestamento há uma maior proteção e integralidade das APP, principalmente devido às certificações que as empresas desse ramo possuem que prezam pela manutenção da biodiversidade e o seguimento da legislação florestal vigente.

Fica evidenciada a notória necessidade de um projeto que possua técnicas mitigatórias para a recomposição da vegetação nativa na APP, devido à degradação ambiental relacionada com a falta de planejamento do uso do solo, causando fragilidade nas zonas de conflito. Deste modo, ressalta-se a necessidade da recomposição da vegetação arbórea nas matas ciliares (SOARES et. al., 2002), tanto ao longo das margens dos cursos d'água quanto das nascentes, utilizando-se de técnicas de recuperação de áreas degradadas e restauração florestal, assim preservando o meio ambiente de maneira a unificar o contexto jurídico frente ao código florestal.

\section{CONCLUSÃO}

O uso de técnicas de geoprocessamento na classificação do uso e ocupação do solo e a identificação de conflitos de uso em APP na microbacia do Córrego do Petiço, tendo como base a legislação florestal mostraram-se bastante satisfatória, podendo ser uma ferramenta de caráter indispensável em futuros planos de recuperação de áreas degradadas e restauração florestal.

A utilização do SIG IDRISI e sua capacidade de integração possibilitaram com facilidade e rapidez o mapeamento das unidades da paisagem, permitindo a elaboração de um banco de dados digital, fornecendo resultados confiáveis referente 
às APP e as diferentes zonas conflitantes do uso da terra em um pequeno intervalo de tempo.

As zonas de APP (284,77 ha) do Córrego do Petiço não estão integralmente preservadas conforme preza a legislação pertinente - Lei no 12.727 , de 17 de outubro de 2012 - e que estas vêm sendo ocupadas indevidamente, principalmente por pastagem (15,01 ha) e reflorestamento (4,85 ha).

Os resultados mostram que são necessárias medidas mitigadoras para a proteção dos recursos hídricos no Córrego do Petiço, como a recomposição da vegetação nativa, principalmente nas zonas de APP, pois a degradação de tais áreas pode por em risco o futuro hídrico da microbacia a médio-longo prazo.

\section{REFERÊNCIAS}

BRASIL. Resolução CONAMA $n^{\circ} 303$, de 20 de Março de 2002, dispõe sobre as áreas de preservação
<http://www.mma.gov.br/port/conama/res/res02/res30302.html>. Acesso em: 27 jun., 2014.

BRASIL. Lei ${ }^{\circ} 12.727$, de 17 de outubro de 2012. Altera a Lei no 12.651, de 25 de maio de 2012, que dispõe sobre a proteção da vegetação nativa; altera as Leis nos6. 938, de 31 de agosto de 1981 , 9.393, de 19 de dezembro de 1996, e 11.428, de 22 de dezembro de 2006; e revoga as Leis nos 4.771, de 15 de setembro de 1965, e 7.754, de 14 de abril de 1989, a Medida Provisória no 2.166-67, de 24 de agosto de 2001, o item 22 do inciso II do art. 167 da Lei no 6.015, de 31 de dezembro de 1973, e o $\S 20$ do art. 4o da Lei no 12.651, de 25 de maio de 2012. Diário Oficial da União, Brasília, DF, 18 out. 2012. Disponível em: <http://www.planalto.gov.br/ccivil_03/_Ato2011-2014/2012/Lei/L12727.htm>. Acesso em: 13 jul., 2014.

CAMPOS, S.; SILVEIRA, G. R. P.; PISSARA, T. C. T.; FELIPE, A. C.; GARCIA, Y. M.; CAMPOS, M. Diagnóstico do uso do Solo em APP na Microbacia do Córrego Santo Antonio - São Manuel (SP) em Função da Legislação Ambiental. Revista Geoaraguaia, Barra dos Garças, v. 3, p. 198-210, 2013.

CEPAGRI. Centro de Pesquisas Meteorológicas e Climáticas Aplicadas à Agricultura. Clima dos municípios paulistas - Botucatu. 2014. Disponível em: <http://www.cpa.unicamp.br/outrasinformacoes/clima_muni_086.html>. Acesso em: 15 jun. 2014.

GARCIA, Y. M. Aplicação do Código Florestal como Subsídio para o Planejamento Ambiental na Bacia Hidrográfica do Córrego do Palmitalzinho - Regente Feijó - São Paulo. Trabalho de conclusão (Bacharelado - Geografia) - Universidade Estadual Paulista, Faculdade de Ciências e Tecnologia, Presidente Prudente, 2011, $145 \mathrm{f}$.

IBGE. Instituto Brasileiro de Geografia e Estatística. Carta topográfica: Folha de Botucatu (SF-22-Z-BVI-3). Serviço gráfico do IBGE, 1969. Escala 1:50.000.

PINTO, L. V. A.; FERREIRA, E; BOTELHO, S. A.; DAVIDE, A. C. Caracterização física da bacia hidrográfica do Ribeirão Santa Cruz, Lavras, MG e uso conflitante da terra em suas áreas de preservação permanente. Revista Cerne, Lavras, v.11, n.1, p.49 - 60, 2005. 
PIROLI, E. L. Geoprocessamento na determinação da capacidade e avaliação do uso da terra do município de Botucatu - SP. Tese (Doutorado em Agronomia/Energia na Agricultura) - Universidade Estadual Paulista, Faculdade de Ciências Agronômicas, Botucatu, 2002, 108 f.

SILVA, E. Código Florestal Brasileiro: função e áreas de preservação permanente. In: SIMPÓSIO INTERNACIONAL SOBRE ECOSSISTEMAS FLORESTAIS. Belo Horizonte, MG. Anais do Simpósio Internacional sobre Ecossistemas Florestais, Belo Horizonte, Editado por Edufmg, 1996. p. 48-55.

SOARES, V. P.; MOREIRA, A. A.; RIBEIRO, J. C.; RIBEIRO, C. A. A. S.; SILVA, E. Avaliação das áreas de uso indevido da terra em uma micro-bacia no município de Viçosa, $M G$, através de fotografias aéreas e Sistemas de Informação Geográfica. Revista Árvore, Viçosa, v. 26, n. 2, p. 243-251, 2002.

USGS. U.S. Department of the Interior/ U.S. Geological Survey. Browse Images. Disponível em: <http://glovis.usgs.gov/AboutBrowse.shtml>. Acesso em: 25 mar., 2014. 